\title{
A block model development for intelligent control of the switches operating apparatus position in the electrical interlocking system
}

\author{
Sunnat Boltayev", Bobomurod Rakhmonov, Obid Muhiddinov, Aziz Saitov, and Zohid \\ Toshboyev
}

Tashkent State Transport University, Tashkent, Uzbekistan

\begin{abstract}
In this scientific article, we developed a model of block $\mathrm{C}$ that controls the position of the switches. A mathematical model of the block was calculated using a two-layer neural network along with the blocks of the block. An imitation model of the switch control block using the SoDeSys program is presented.

In the modeling process, it was studied that a multilayer neural network consists of one or more hidden layers of neurons-the entrance, exit, and the neurons located between them. And block $\mathrm{C}$ was determined that it was possible to model with the help of a 2-layer neural network and was expressed in the form of the following layers:

1-in the hidden layer: in the $\mathrm{C}$ block, the PK and MK relays are listed. This process indicated that the data coming from the PS or PST block would receive the PK and MK releases. At this layer, it is determined in which position the switches are located, and the data is transferred to the next layers.

2-in the hidden layer: the VZ relay in the $\mathrm{C}$ Block is indicated. Information coming from $\mathrm{PK}$ and $\mathrm{MK}$ relays shows the $\mathrm{VZ}$ relays acceptance process. In this layer, it is determined whether the switch is cut or not, and information is transferred to the next layers. In this layer, a certain position of the pushed conductor is determined
\end{abstract}

\section{Introduction}

At present, the reliable operation of automation and telemechanic relay devices and systems in railway transport ensures the safety of trains. However, after the speed of the rolling stock exceeds $160 \mathrm{~km} / \mathrm{h}$, relay devices and systems add additional time to ensure the safety of trains [1]. Ensuring the safety of trains at high speeds is currently achieved through the use of microprocessor-based devices and systems.

To ensure the safety of train traffic at the station, the devices of electrical interlocking systems must ensure the following following the rules of use of equipment $[2,3]$ :

- mutual locking of switches and traffic lights( closure);

- control of switch cutting with simultaneous closing of the traffic light bordering on this route;

*Corresponding author: sunnat_3112@list.ru 
- control of switch sections, road occupancy, and switch condition on the control panel;

- Possibility to route or separate traffic lights and traffic lights;

- maneuvering actions on shunting stoplight indicators;

- transfer the switches to local government, if necessary

Following the rules of technical use of electrical interlocking devices are not allowed $[2,3]$ :

- opening the entrance traffic light when the route is busy;

- moving the switch under the rolling stock;

- opening traffic lights corresponding to this route if the switches are not placed in the appropriate position;

- switching the switch entering the route or opening the traffic light of the opposite route.

At present, most of the relay electrical interlocking systems are block electrical interlocking systems. The block electrical interlocking system consists of the dial and executive groups. Executive group schemes control the locking (closing) of routes and the opening of traffic lights and the cancellation of routes, automatic and artificial separation. The Executive Group has the following blocks VI, VII, VIII, VD, Vx, VxD, MI, MII, MIII, P, UP, SP, PS, PST, and C [2-18].

\section{Methods}

Of these, block $\mathrm{C}$ is designed to check the suitability of the switch position on the route being installed and to disconnect the route installation chain. Block $\mathrm{C}$ is set separately for each switch conductor in binary switches and single switches. Block C consists of PK relays that control the plus position of the switch, MK, which controls the minus position, and VZ, which controls the cross-section of the switch (Figure 2.).

a)

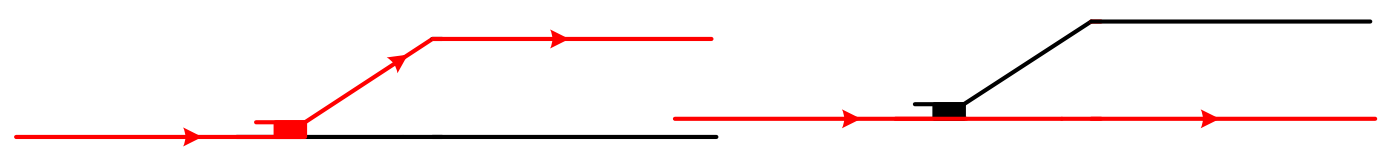

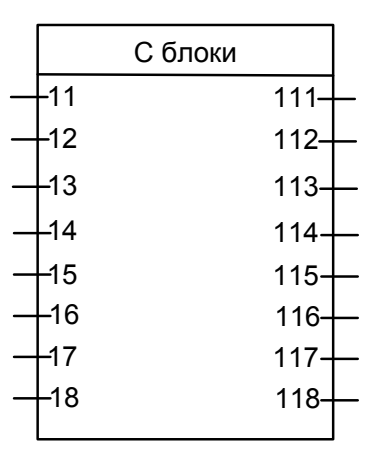

b)

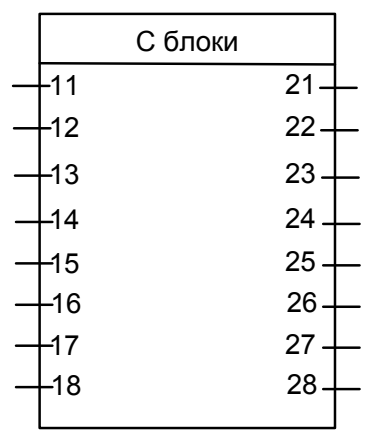

Fig. 1. Block $\mathrm{C}$ is connected to the route setup and disconnection chain.

Block $\mathrm{C}$ connects the route setup and disconnection chain depending on the position of the switch. (Figure 1a, b). If the switch is in the plus position, block $\mathrm{S}$ to set the route and disconnect the chain "11 - 21", "12 - 22", "13 - 23", "14 - 24", "15 - 25", "16 - 26", "1727", "18 - 28" (Figure 1a) through the chain, if in the minus position "11 - 111", "12 - 
112", "13 - 113", "14 - 114", "15 - 115", "16 - 116", "17 - 117", "18 - 118" (Figure 1b), connects through the chain, if the switch loses control, the chain is disconnected via the contact of the $\mathrm{VZ}$ relay in the block. When other inputs and outputs of block $\mathrm{C}$ are not used in the route setup and disconnection chain, they use the relay PK, MK, VZ, if necessary, receive a repeater $\mathrm{PK}, \mathrm{MK}, \mathrm{VZ}$ relay and display the status of the switch.

The position of the relays of block $\mathrm{C}$ was calculated using discrete mathematics. This article presents a mathematical calculation of the block using its neural set to accurately control its state.

A multilayer neural network consists of a neural network consisting of one or more latent layers of neurons entering, exiting, and located between them. In addition to the input and output layers, these neural networks also include intermediate, latent layers. Such networks have much greater potential than single-layer neural networks, but methods for preparing latent layer neurons have been developed relatively recently.

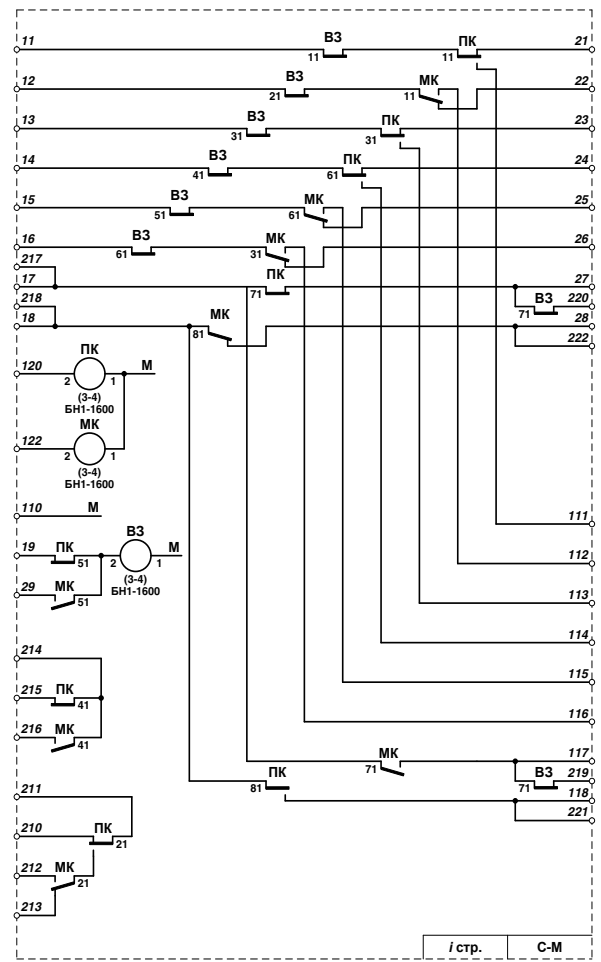

Fig.2. Appearance of the block controlling the position of the switch.

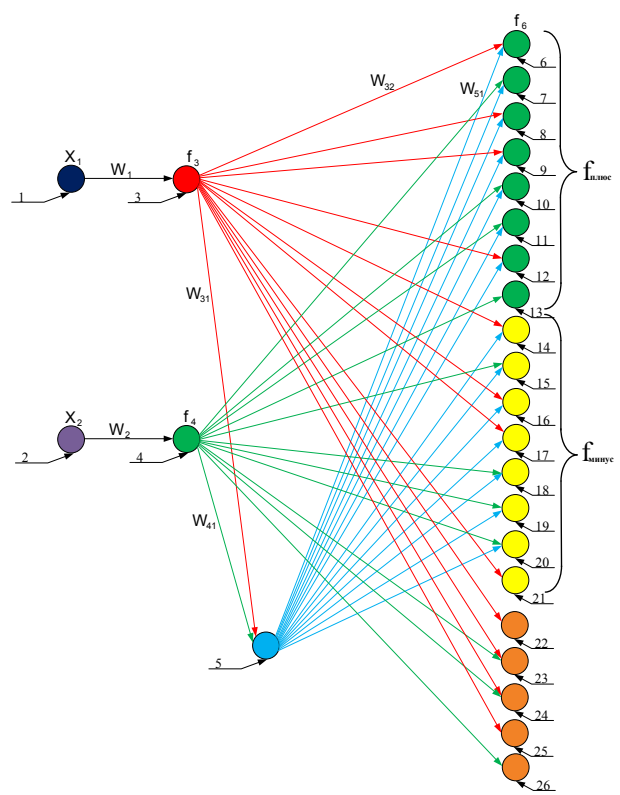

Fig.3. Control the status of the switch using a two-layer neural network.

\section{Results and Discussion}

The work of the latent layers of neurons can be compared to the work of a large factory. The factory product (output signal) is assembled step by step on the machines. Some intermediate result is obtained after each machine. Hidden layers also convert input signals into some intermediate outputs.

In Figure 1, we consider the operation of block $\mathrm{C}$, taking into account the inputs and outputs according to the model of an artificial neuron set [19-25]. In doing so, we build a set of neurons in two layers. Its layers are listed in Table 1. 
In this case, the equations on the chains of switch conductors are constructed. The article presents the equation of the chain "11-21".

In the input layer: The data of the cases of pullus (1) or minus (2) of the switch coming from the PS or PST blocks are given in the form X1 and X2. This layer stores data from the PS or PST blocks and transmits the data to the C block.

In the 1st hidden layer: relays PK (3) and MK (4) in block C are included. It is shown that the data coming from the PS or PST block is received by the relays PK (f3) and MK (f4). In this layer, the position of the switch is determined, and the data is transmitted to the next layers.

$$
\begin{aligned}
& f_{3}=x_{1} w_{1}, y_{3}\left(f_{3}\right)=y_{3}\left(x_{1} w_{1}\right) \\
& f_{4}=x_{2} w_{2}, y_{4}\left(f_{4}\right)=y_{4}\left(x_{2} w_{2}\right)
\end{aligned}
$$

In hidden layer 2: $\mathrm{VZ}$ relay in block $\mathrm{C}$ is shown. It shows the process of receiving data from the relay PK and MK VZ relay. In this layer, it is determined whether the switch is cut or not, and information is passed to the next layers. In this layer, the exact position of the switch conductor is determined (Figure 4, a,b,c,d).

$$
f_{5}=y_{3} w_{32}+y_{4} w_{41}, y_{5}\left(f_{5}\right)=y_{5}\left(y_{3} w_{32}+y_{4} w_{41}\right)
$$

In the output layer: in the C block "11 - 21", "12 - 22", "13 - 23", "14 - 24", "15 - 25", "16 - 26", "17 - 27", "18 - 28", "11 - 111", "12 - 112", "13 - 113", "14 - 114", "15 - 115", "16 - 116", "17 - 117", "18 - 118", the indication chains are "turn on the green, yellow and red lights" and the "most commonly checked circuit" chains are shown. In this layer: the reception of data from the previous hidden layers and the indication chains in the plus or minus position of the switch is carried out by the activation of the chains "turn on the green, yellow and red lights" and "check the circuit".

$$
f_{6}=y_{3} w_{31}+y_{5} w_{51}, y_{6}\left(f_{6}\right)=y_{6}\left(y_{3} w_{31}+y_{5} w_{51}\right)(4)
$$


Table 1. Propagation of a two-layer neural network of the switch block.

\begin{tabular}{|c|c|c|c|}
\hline Layers & № & Functions & Contents \\
\hline \multirow{2}{*}{ Input } & 1. & & PC access \\
\hline & 2. & & Access to MK \\
\hline \multirow{3}{*}{ Hidden layers } & 3. & & PC control \\
\hline & 4. & & MK control \\
\hline & 5. & & Access to $\mathrm{VZ}$ \\
\hline \multirow{21}{*}{ Output } & 6. & & "11-21" chains \\
\hline & 7. & & "12-22" chains \\
\hline & 8. & & "13-23" chains \\
\hline & 9. & & "14 - 24" chains \\
\hline & 10. & & "15-25" chains \\
\hline & 11. & & "16-26" chains \\
\hline & 12. & & "17-27" chains \\
\hline & 13. & & "18-28" chains \\
\hline & 14. & & "11 - 111" chains \\
\hline & 15. & & "12-112" chains \\
\hline & 16. & & "13 - 113" chains \\
\hline & 17. & & "14 - 114" chains \\
\hline & 18. & & "15 - 115" chains \\
\hline & 19. & & "16 - 116" chains \\
\hline & 20. & & "17 - 117" chains \\
\hline & 21. & & "18-118" chains \\
\hline & 22. & & "Start Z" indication chain \\
\hline & 23. & & "Start K" indication chain \\
\hline & 24. & & "Start J" indication chain \\
\hline & 25. & & $\begin{array}{l}\text { From PC to compatibility checker } \\
\text { circuit }\end{array}$ \\
\hline & 26. & & $\begin{array}{l}\text { From MK to the conformity checker } \\
\text { circuit }\end{array}$ \\
\hline
\end{tabular}




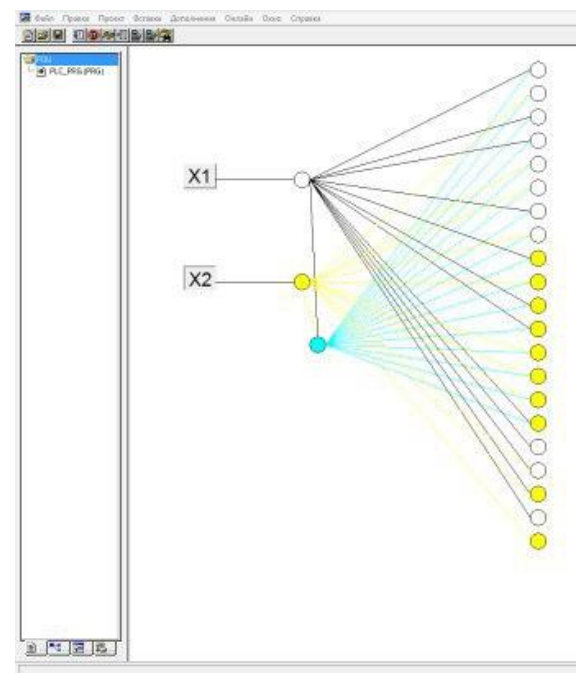

a)

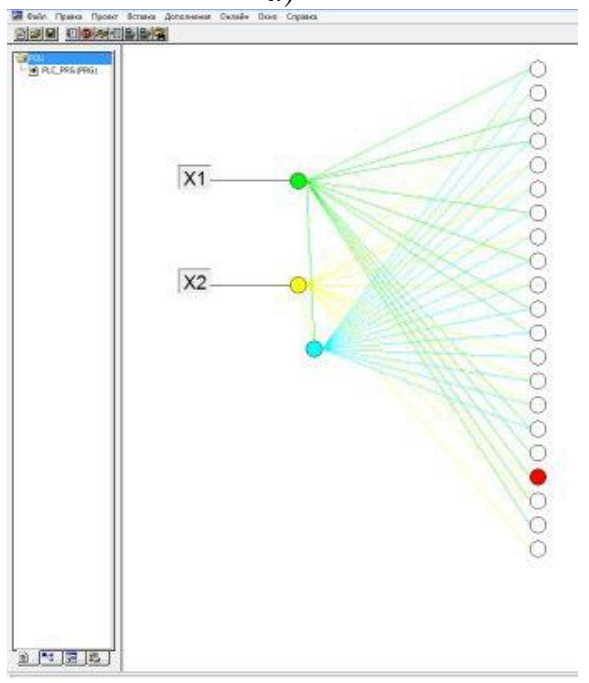

c)

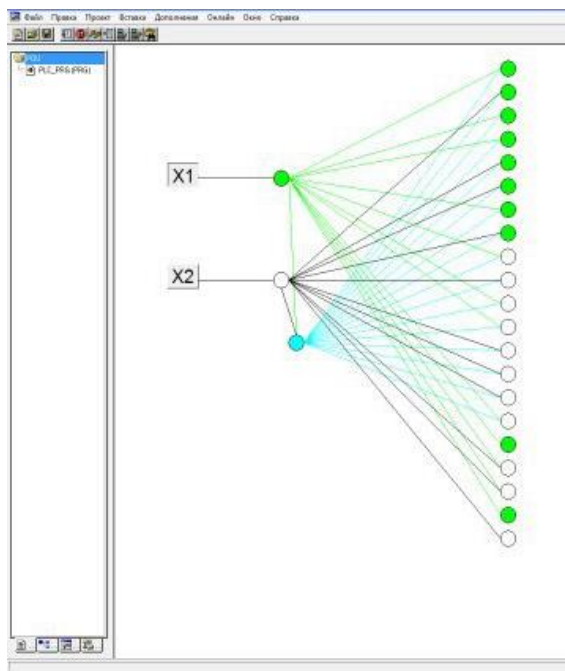

b)

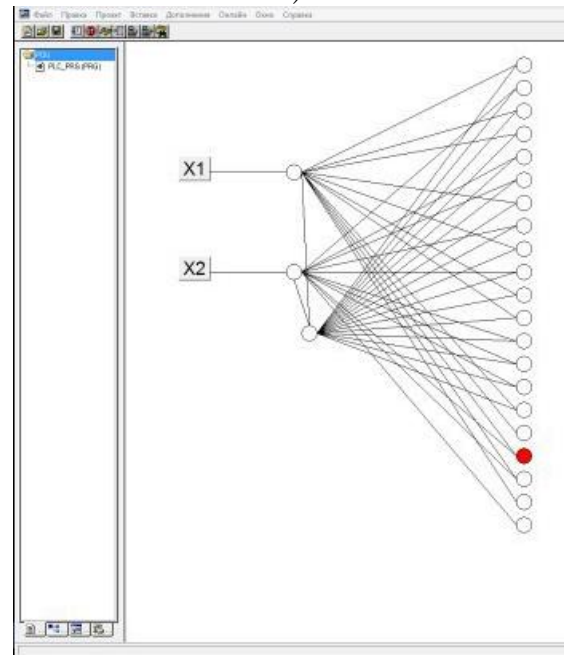

d)

Fig.4. Simulation of the switch status using CoDeSys program: a-switch in the minus position, bswitch in the plus position, s-switch in the faulty state (all functions of the hidden layer determining the status of PK, MK and VZ relays are active), d-switch in the faulty state (PK, MK and all functions of the latent layer determining the status of the $\mathrm{VZ}$ relays are inactive)

\section{Conclusions}

In conclusion, it can be said that the unit that controls the status of the switches, after determining the exact position of the switch, activates the relay indicating the status of the switch and activates the indicator lights corresponding to the indication chains. In this scientific paper, a model of switch status detection using a two-layer neural network and an imitation model using SoDeSys software were created. This allows the electrical interlocking systems to intelligently determine the data when determining the position of the module or block that controls the position of the switches. 


\section{References}

1. Boltayev S.T., Gayubov T.N., Rakhmonov B.B., Kosimova Q.A., Ergashov B.G. The creation of microprocessor-controlled modules for AC and DC conductors Journal of critical reviews (JCR), 7 (17): pp. 2183-2189. 10.31838/jcr.07.17.268.(2020)

2. The rules of technical operation of the railway of the Republic of Uzbekistan. Uzgosjeldornadzor, Tashkent, p 159. (2001).

3. Sapojnikov V. V, Technical operation of the system of railway automation and telemechanics.- M .: Marshrut, -p 336. (2003).

4. / Vl.V. Sapozhnikov, B.N. Elkin, I.M. Kokurin [and others]; Edited by V.V. Sapozhnikov, Station systems of automation and telemechanics: textbook for universities of railway transport - M.: Transport,.p 423. (1997)

5. Belyazo I.A. Route-relay centralization: a textbook / I.A. Belyazo, V. R. Dmitriev. 3rd ed., Revised and supplemented. - M.: Transport,.- p 320. (1974).

6. Reznikov Yu.M. Electric drives of railway automation and telemechanics, Yu.M. Reznikov.- M.: Transport,.-p 288. (1985).

7. Kononov V.A, V.A. Kononov, A.A. Lykov, A.B. Nikitin. Fundamentals of designing the electrical centralization of intermediate stations, textbook - 2nd ed., Additional and revised. - M .: FSBEI UMC by education at railway transport, p 348. (2013).

8. R.Sh. Valiev, Sh.K. Valiev, Two-wire switch control circuit with a PS starting block with central power supply, Yekaterinburg: Webster LLC, - p 48. (2011).

9. Valiev, Sh.K. Sh.K. Valiev, R.Sh. Valiev, Studying and research of control circuits of switch electric drives: textbook.-method. Manual / - Yekaterinburg: UrGUPS,.- 87, [1]. (2015).

10. Pereborov AS, Bryleev AM, Efimov V.Yu., Kokurin IM, Kondratenko LF Telecontrol of switches and signals, Textbook for universities railway transport, Ed. Pereborova A.S.M, Transport, (1981).

11. A.S. Pereborov, A.M. Bryleev, V.Yu. Efimov, I.M. Kokurin, L.F. .Kondratenko; Edited by Telecontrol of switches and signals: a textbook for high schools of railway transport, .- 3rd ed., revised and enlarged. -Moscow: Transport,.- p 390. (1981)

12. Vl. V. Sapozhnikov, V. A. Kononov, S. A. Kurenkov, A. A. Lykov, O. A. Nasedkin, A. B. Nikitin, A.A. Prokofiev, M.S. Tryasov; Edited by V.V. Sapozhnikov, Microprocessor centralization systems: a textbook for technical schools and colleges of railway transport, - Moscow: State Educational Institution "Educational and Methodological Center for Education in Railway Transport". P 398 . (2008)

13. Theeg G, Vlasenko S, Railway Signalling and Interlocking - International Compendium, Eurailpress 2009 (Teeg G. Vlasenko S. Automation and telemechanics systems on the world's railways, Intext Eurailpress 2009. p 475.) (2009).

14. Microprocessor-based centralization system for switches and signals Ebilock-950. M., TRANSISDAT, 2008 - p 368. (2008)

15. Soroko V.I., Fotkina Zh.V. Equipment of railway automation and telemechanics: Reference: in 4 books. Prince 2. - 4th ed. - M.: NPF PLANETA LLC, p 1048. (2013).

16. Nikitin A.B., Bushuev S.V. A generalization of the development trends of electric centralization devices and the experience of replication of computer systems for operational control of train traffic at stations, Transport of the Urals., (2). (2006)

17. Valiev R.Sh. Two-wire switch control circuit with a PS starting block with central power supply, R.Sh. Valiev, Sh.K. Valiev Yekaterinburg: Webster LLC, - p 48. (2011).

18. Valiev, Sh.K. Studying and research of control circuits of switch electric drives: textbook.-method. Manual / Sh.K. Valiev, R.Sh. Valiev. - Yekaterinburg: UrGUPS, p 87. (2015) 
19. S. Haykin. Neural set: full course. 2nd ed. M., "Williams," (2006).

20. S.Haykin. Neural Networks and Learning Machines. 3rd Edition. Pearson, (2018).

21. D.A. Tarkhov. Neural networks. Models and algorithms. M., Radio Engineering, (2005).

A. N. Vasiliev, D. A. Tarkhov. Neural modeling. Principles. Algorithms. Applications. SPb.: Publishing house of Polytechnic. University,. ISBN 978-5-7422-2272-9. (2009).

22. G.E. Yakhyaeva. Foundations of the theory of neural networks. Internet University of Information Technologies, Open Systems Publishing House.

23. V.V.Kruglov, M.I.Dli, R.Yu. Golunov. Fuzzy logic and artificial neural networks. Fizmatlit, (2001).

24. C.C.Aggarwal. Neural Networks and Deep Learning. A Textbook. Springer International Publishing A.G. DOI 10.1007/978-3-319-94463-0 ISBN 978-3-31994462-3. (2018) 